\title{
Damage and disturbance to coral and sponge habitat of the Aleutian Archipelago
}

\author{
Jonathan Heifetz*, Robert P. Stone, S. Kalei Shotwell \\ NOAA, National Marine Fisheries Service, Alaska Fisheries Science Center, Auke Bay Laboratories, \\ Ted Stevens Marine Research Institute, 17109 Pt. Lena Loop Road, Juneau, Alaska 99801-8344, USA
}

\begin{abstract}
Video imagery was examined to quantify seafloor disturbance and damage to corals and sponges relative to fishing practices in the central Aleutian Islands of Alaska. Corals and sponges were classified as damaged if they had broken skeletons, missing or broken branches, were torn (i.e. sponges) or detached from the seafloor, or were attached but lying on the seafloor. Disturbance was defined as any alteration to the seafloor or biota caused by fishing gear or natural events. Overall, $14 \%$ of corals and $21 \%$ of sponges were damaged, and disturbance was widespread and evident on most video transects. The proportion of damaged corals was significantly less $(p=0.003)$ in areas with little or no bottom trawl fishing versus areas with medium and high intensity bottom trawl fishing. For other gear types, damage was not significantly different among fishing levels. Damage for all corals was $7 \%$ in untrawled areas, $7 \%$ in low-intensity areas, $14 \%$ in medium-intensity areas, and $49 \%$ in high-intensity areas. For gorgonians, $5 \%$ were damaged in untrawled areas and $23 \%$ were damaged in high-intensity areas. For hydrocorals, damage was $10 \%$ in untrawled areas and $53 \%$ in medium-intensity areas. Hydrocorals were absent from high-intensity areas. About $40 \%$ of sea whips were damaged in high-intensity areas versus $1 \%$ in other areas. While some protective measures have been implemented to halt the expansion of bottom trawl fishing to unfished areas, the conservation of coral and sponge habitat in fished areas is still of primary concern.
\end{abstract}

KEY WORDS: Deep-sea coral $\cdot$ Sponge $\cdot$ Damage $\cdot$ Habitat $\cdot$ Fishing gear effects

\section{INTRODUCTION}

A unique feature of the benthic environment of the Aleutian Archipelago is the presence of a highly diverse and abundant coral and sponge community. Corals and sponges are a ubiquitous feature of the Aleutian Islands seafloor, there is a high degree of endemism, and coral abundance far exceeds that in most other high latitude areas of the world (Heifetz 2002, Heifetz et al. 2005, Malecha et al. 2005, Stone 2006, Stone \& Shotwell 2007). A range of issues, such as biodiversity protection, conservation of seafloor habitats, and the role of deep-sea corals as fish habitat, places significance on understanding impacts of fishing activities on coral and sponge communities (Morgan et al. 2005). In addition to the rich coral and sponge fauna, the Aleutians support important fisheries for groundfish and crabs (Hiatt 2007). Fishing gear used in these fisheries can disturb coral and sponge habitat, since commercial fish and crab species tend to associate with corals (Heifetz 2002, Stone 2006). Since many coral species are known to be extremely long-lived and slow-growing, recovery from gear damage may be extremely slow (Andrews et al. 2002, 2009, this Theme Section). Although some protective measures have been implemented (DOC 2006), conservation of this unique community and the habitat it provides continues to be a challenging problem in the area's fisheries that use bottom-contact gear.

Fishery bycatch records have been used to assess adverse impacts to corals (e.g. Shester \& Ayers 2005). However, such records do not account for damaged 
corals and sponges that remain on the seafloor. We focus on direct seafloor observations of damage and disturbance to coral and sponge habitat and relate findings to observed fishing practices. We extend the work of Stone (2006) by expanding observations to deeper water $(>360 \mathrm{~m})$, assessing damage to specific groups of coral taxa, and relating findings to the spatial distribution of fishing effort for specific gear types. Commercial fishing operations in the Aleutian Islands that can potentially affect benthic habitat use 4 types of bottom-contact gear: (1) bottom trawls, (2) pots, (3) longlines with hooks, and (4) longlines with crab pots. The main objective of the present study is to assess whether damaged corals are more prevalent in heavily fished areas than in areas with little or no fishing. To meet this objective, video imagery of the seafloor was collected. Damaged corals and sponges were enumerated and disturbance to seafloor substrate was evaluated.

\section{MATERIALS AND METHODS}

Video of the seafloor was collected using the occupied submersible 'Delta' in 2003 and 2004 and the remotely operated vehicle (ROV) 'Jason II' in 2004. The 'Delta', a 2-person submarine, conducted 22 video strip transects. The length of the 'Delta' transects ranged from 280 to $2075 \mathrm{~m}$ and depth ranged from 56 to $330 \mathrm{~m}$. Following Stone (2006), video footage of the seafloor was collected with 2 externally mounted cameras. The primary camera was mounted with the imaging plane directed perpendicular to the seafloor with the camera lens at a near-constant altitude of $80 \mathrm{~cm}$ when the submersible was in contact with the seafloor. Width of the image area was not fixed (varied between 80 and $400 \mathrm{~cm}$ ) and depended on the submersible's altitude. The average width for all transects was $155 \mathrm{~cm}$. A second camera was mounted laterally with the imaging plane directed at a $45^{\circ}$ angle to the seafloor. This view was used to enumerate biota in areas where the seafloor was near vertical (approximately $>70^{\circ}$ ). In addition, the video cameras recorded 2 parallel laser marks $20 \mathrm{~cm}$ apart projected onto the seafloor to provide calibration for measurements of the image area width.

The ROV 'Jason II' was used to conduct 5 transects. The length of the 'Jason II' transects ranged from 1916 to $6818 \mathrm{~m}$ and depth ranged from 170 to $2947 \mathrm{~m}$. The video camera used for coral and sponge counts was mounted approximately $2.4 \mathrm{~m}$ above the seafloor. This camera was mounted with the imaging plane directed nearly perpendicular to the seafloor and recorded 2 sets of parallel laser marks (144 and $10 \mathrm{~cm}$ apart) projected onto the seafloor. The perspective provided by this camera and the projected laser marks provided a fixed-width transect of $144 \mathrm{~cm}$.

The total area sampled was $64895 \mathrm{~m}^{2}$. The sampling unit was the video field of view, referred to as a frame. Due to the very large quantity of video data, frames were subsampled on many of the dives at rates of 10 to $50 \%$ in a systematic fashion. For the 'Delta' transects, sampling rates of 10 and $50 \%$ were achieved by sampling every 10th and every other frame, respectively. For all except 1 of the 'Jason II' transects, frames were sampled at a $50 \%$ rate, achieved by sampling 5 adjacent frames and then skipping the next 5 frames, and so on. In total, there were 21885 frames from 27 transects for which data were transcribed. The frequency of samples was highest between 200 and $500 \mathrm{~m}$, which is similar to the availability of seafloor substrates by depth from 0 to $3000 \mathrm{~m}$ (Woodby et al. 2009, this Theme Section). Dive transects were geographically distributed among 9 sites coincident with multibeam seafloor habitat mapping. Further details of the experimental design as well as results from complementary studies are available in Heifetz et al. (2007).

Following Stone (2006), video footage was examined in the laboratory, and corals and sponges were counted if their bases were completely in the field of view. Corals and sponges were classified as damaged if they consisted of broken skeletons, had missing or broken branches, were torn (i.e. for sponges) or exhibited other evidence of injury, were detached from the seafloor, or were attached but overturned and lying in contact with the seafloor. Damage to sponges was determined only for video transects collected via the ROV 'Jason II'.

Coral taxa were classified into 3 groups for the purposes of data analysis: (1) gorgonians (Subclass Octocorallia, Order Gorgonacea); (2) sea whips and sea pens (Subclass Octocorallia, Order Pennatulacea); and (3) hydrocorals (Class Hydrozoa, Order Anthoathecatae). Two other groups were judged to be too deep or infrequent to provide meaningful observations: Radicipes sp. (a deep-water gorgonian) and black corals (Subclass Hexacorallia, Order Antipatharia). Sponge taxa were lumped together into a single group. Stony corals (Subclass Hexacorallia, Order Scleractinia) and soft and stolon corals (Subclass Octocorallia, Orders Alcyonacea and Stolonifera) also occur in Alaska but were not included in our analyses. Assessment of damage to most of these taxa is difficult because stony corals in Alaska are very small and not reef-building, and soft and stolon corals lack a cohesive axial skeleton that may persist after death.

Disturbance to the seafloor was defined as any alteration to the seafloor or associated biota caused by fishing activity or natural events such as underwater landslides. The severity of disturbance was classified based 
Table 1. Categories used to assign seafloor disturbance codes to video transect data

\begin{tabular}{|lc|}
\hline Disturbance code & Description \\
\hline 0 (Absent) & No evidence of disturbance \\
1 (Low) & $>0-9 \%$ of biota and/or substrate \\
& showed evidence of disturbance \\
2 (Medium) & $10-50 \%$ of biota and/or substrate \\
& showed evidence of disturbance \\
3 (High) & 50\% of biota and/or substrate \\
& showed evidence of disturbance \\
\hline
\end{tabular}

on an ordinal scale for depths $<1500 \mathrm{~m}$ (Table 1). Disturbance levels ranged from occasional overturned cobbles with infrequent damaged corals to complete scouring of the seafloor and associated biota. In practice, it was difficult to ascertain whether disturbance level 1 (low) was due to natural events (e.g. predation, senescence) which may mask disturbance caused from fishing gear. In general, when caused by longline gear, disturbance is characterized by detached or tipped over corals and sponges that are not linearly arranged, i.e. there is no distinct pattern to the disturbance because the principal forces, straining shear and entanglement, are not symmetrically distributed on the seafloor (Krieger 2001, Stone 2006).

Commercial fishery data within the study site are available from the National Marine Fisheries Service (NMFS) North Pacific Groundfish Observer Program (AFSC 2009) and the Alaska Department of Fish and Game (ADFG). For pot fisheries, some fishers use single pots and others use longlined pots; however, these are not distinguished from one another in the NMFS data. Note that observed fishing effort does not include longline fisheries that target Pacific halibut Hippoglossus stenolepsis. Data from the NMFS observer database includes duration of bottom trawl hauls, total hooks of longlines, and number of pots, while only pot lift locations were available from ADFG for longlined crab pots. Haul locations in the NMFS observer database are recorded at a lower resolution than the ADFG crab pot lifts (minutes versus seconds = approximately $2 \mathrm{~km}$ vs. $100 \mathrm{~m}$ ). However, we did not have information on the number of ADFG crab pots per haul, and could only estimate the average distance between locations (about $1 \mathrm{~km}$ ). Following Rose \& Jorgensen (2005), we analyzed the NMFS observer data at $5 \mathrm{~km}$ resolution. We analyzed the ADFG crab pot data at 1 and $2 \mathrm{~km}$ resolution. Comparison of damage and disturbance at the 2 levels of resolution indicated that the level of resolution did not substantially influence results. Thus, we only present results for NMFS observer data at the $5 \mathrm{~km}$ resolution and the ADFG crab pot lift data at the $2 \mathrm{~km}$ resolution.
We used the density function in the Spatial Analyst extension of $\operatorname{ArcGIS}^{\circledR} 9$ to create a density surface of the commercial fishing data for the years 2000 to 2004. In this function, values of input features (e.g. number of hooks per fishing location) are summed within a particular search area and divided by the search area size to calculate density (ESRI 2001). The density surface is a grid of cells over the extent of the input data where the value in each cell is the calculated density within the search area of that cell. The search area is defined by a search radius that determined the distance to search for points from each cell in the density surface (ESRI 2001). The values for NMFS observer data were duration for bottom trawls, number of hooks for longlines, and counts for pots. We only used locations for ADFG crab pot lifts since those were the only data available. We created density surfaces with cell sizes of $25 \mathrm{~km}^{2}(5 \times 5 \mathrm{~km})$ for NMFS observer data and $4 \mathrm{~km}^{2}$ $(2 \times 2 \mathrm{~km})$ for ADFG data.

In order to intersect the commercial fishing density surface (raster data) with the coral disturbance and damage data (vector data), we reclassified the cells of the density surface into 4 levels of commercial fishing intensity. We defined zero, low, medium, and high observed fishing intensity by using the quantile distribution of the density values within each density surface. We then used the intersect function to match a fishing intensity to each point of the disturbance and coral damage data.

Treating each dive as an independent observation, we used ANOVA to test for statistically significant differences in the proportion of damaged corals among fishing intensity levels, and the Kruskal-Wallis (KW) test to test for differences in seafloor disturbance values among fishing intensity levels (Sokal \& Rohlf 1969). There was not a sufficient sample size to assess sponge damage relative to fishing intensity levels, because sponges were enumerated for damage only on the $5 \mathrm{ROV}$ dives. The non-parametric KW test was used because seafloor disturbance is an ordinal variable and parametric methods such as ANOVA are not appropriate. Ideally, such analyses would account for possible interactions, such as that between dive location and damage levels. Such an analysis was not possible because only a few dives crossed multiple areas of different fishing intensity. For example, for bottom trawling only 2 dives crossed more than 1 level of fishing intensity. Thus, single factor analyses were performed. To normalize damage proportions $p$, the arcsine transformation arcsin $\sqrt{p}$ was used (Sokal and Rohlf 1969). Two a priori tests were performed. One tested whether the values differed among the 4 levels of commercial fishing intensity. The other tested whether values differed among areas with little or no fishing (levels 0 and 1 ) versus areas with medium or high fishing intensity (levels 2 and 3 ). 


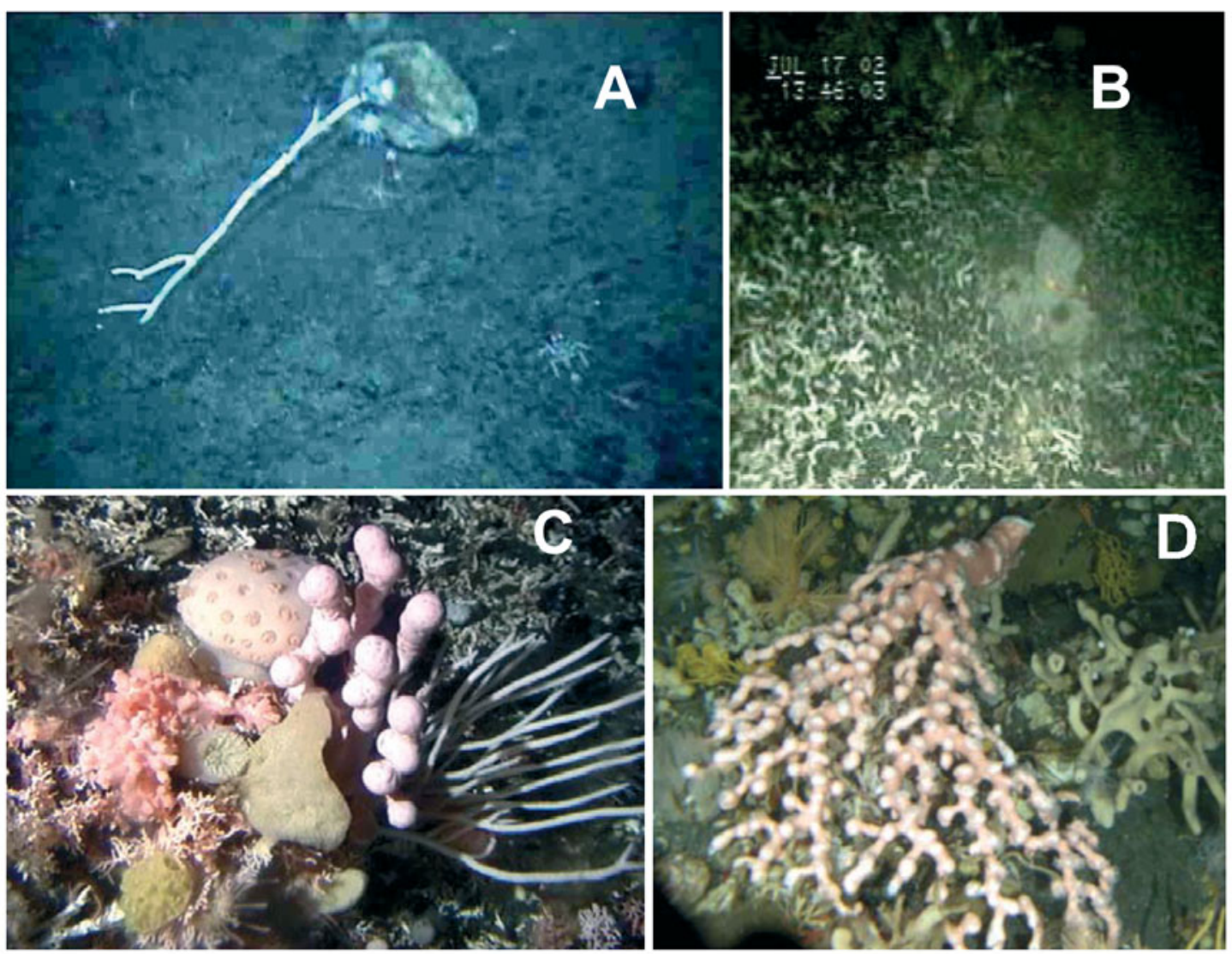

Fig. 1. Examples of damage to coral in the central Aleutian Islands. (A) Bamboo coral (Isididae) attached but overturned and lying in contact with the seafloor; (B) hydrocoral skeletons; (C) a small bubblegum coral Paragorgia arborea, soft coral Anthomastus sp., stolon coral Clavularia sp., hydrocorals, demosponges, and a sea anemone residing at the edge of a path littered with hydrocoral skeletons; (D) P. arborea detached from the seafloor

\section{RESULTS}

Damaged corals were observed on all video transects. Examples of observed damage to corals are shown in Fig. 1. Overall, $14 \%$ of corals and $21 \%$ of sponges were damaged. Hydrocorals had the highest incidence of damage $(22 \%)$, followed by sponges $(21 \%)$, and sea whips and sea pens (18\%) (Fig. 2). The incidence of damaged corals and sponges was generally greatest at depths $<400 \mathrm{~m}$ (Fig. 3). At depths more than $800 \mathrm{~m}$, which is deeper than almost all fishing operations, there was still some damage. Most damage at these depths can be considered background levels from natural events such as swift currents and landslides. The highest level of damage occurred at depths of 100 to $200 \mathrm{~m}$, where almost half of the sea whips were knocked over or had broken axial skeletons.

Disturbance to the seafloor was widespread and evident on $88 \%$ of the video transects. There was considerable variability in disturbance among sites, among transects within sites, and within individual transects. For example, disturbance values averaged 1.8 and

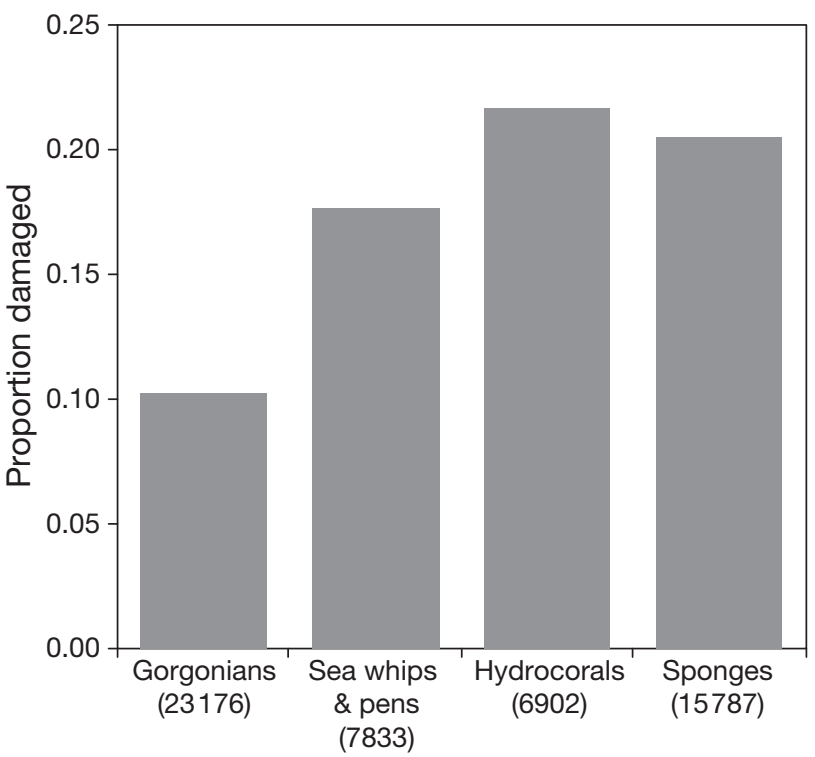

Fig. 2. Proportion of observed corals and sponges damaged in the central Aleutian Islands based on video transects of the seafloor. Number of specimens examined is in parentheses 

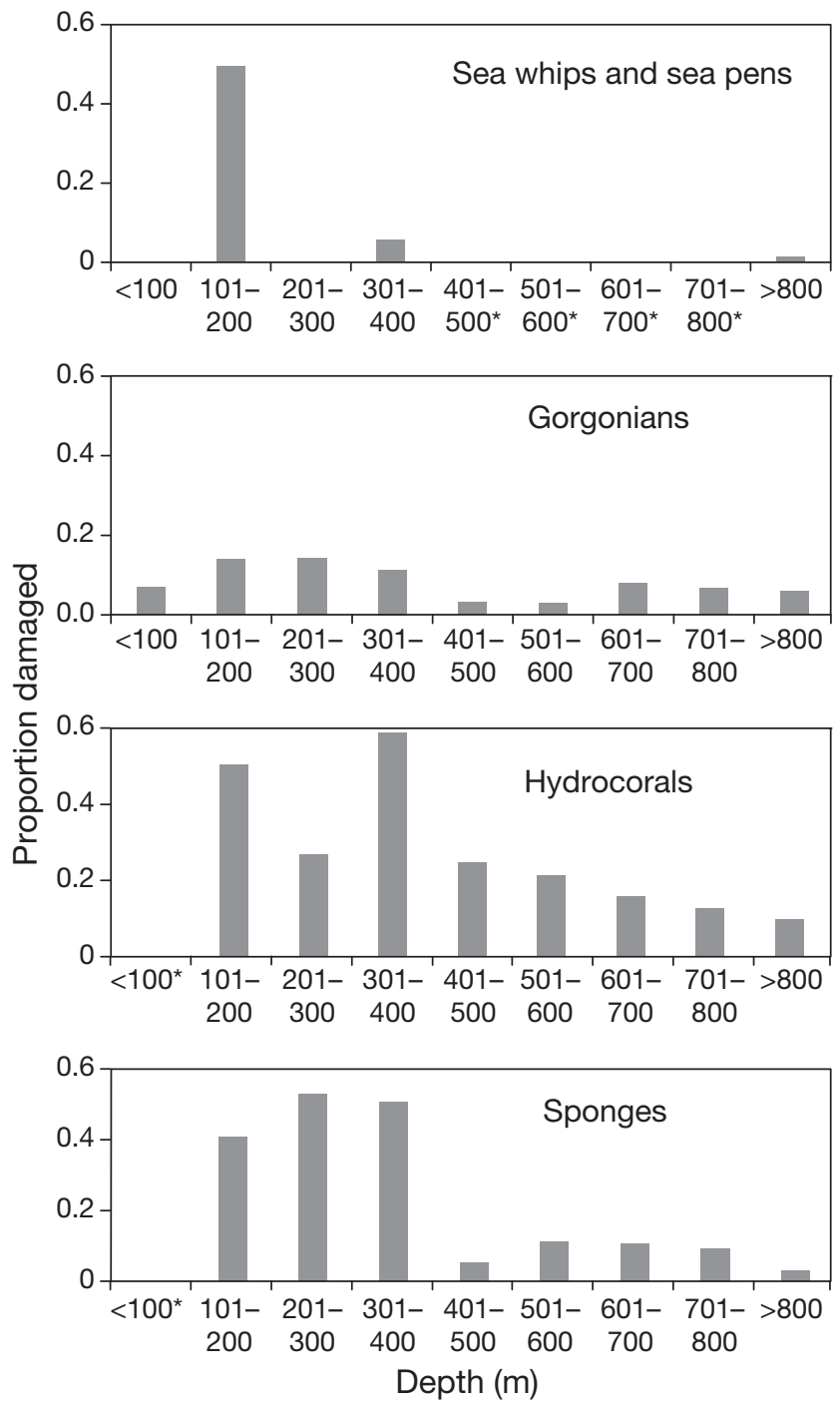

Fig. 3. Proportion of taxa with damage by depth in the central Aleutian Islands. Depths with no data for a particular taxa are denoted by an asterisk

ranged from 0.0 to 3.0 for a particular 'Delta' transect (no. 5997). At a nearby transect (no. 5996) conducted at the same depth range, disturbance values averaged 0.1 and ranged from 0.0 to 0.4 . Overall, the depth distribution of disturbance levels was multimodal with peaks around 170,400, and $650 \mathrm{~m}$ (Fig. 4). In water deeper than $700 \mathrm{~m}$, average disturbance was always less than 0.9 (mean $=0.1$ ) and medium and heavy disturbance was absent (Fig. 4). In water $<700$ m, disturbance levels averaged 0.9 , and $30 \%$ of the video frames had fishing intensity levels $\geq 2$ (medium and high).

Disturbance caused by landslides was evident primarily on a single dive. This area was characterized as a steep slope of coarse volcanic sediment with scattered cobbles and boulders. Within the slide area, only $6 \%$ of corals and sponges were characterized as dam- aged, perhaps because most had been removed by the slide or significant coral and sponge recruitment had occurred since the event.

Fisheries that use bottom-contact gear mostly utilize water depths of 50 to $850 \mathrm{~m}$ (Fig. 5). Most longlining with hooks occurred at depths of 75 to $200 \mathrm{~m}$, targeting Pacific cod Gadus macrocephalus, and at depths of 300 to $750 \mathrm{~m}$, targeting sablefish Anoplopoma fimbria. Bottom trawling occurred mostly in depths of 75 to $200 \mathrm{~m}$ and extended to about $325 \mathrm{~m}$, targeting Atka mackerel Pleurogrammus monopterygius, rockfish Sebastes spp., and Pacific cod. Longlining with crab pots, targeting golden king crab Lithodes aequispinus, occurred mostly at depths of 150 to $600 \mathrm{~m}$. Pot fisheries that targeted Pacific cod occurred at depths of 50 to $150 \mathrm{~m}$ and pot fisheries that targeted sablefish occurred at depths of 400 to $800 \mathrm{~m}$.

The geographic distribution of fishing intensity within the study area differed by gear type (Fig. 6). Bottom trawling and pot fishing were more patchily distributed than longlining with hooks. There was a large degree of overlap for some of the gear types, and under those circumstances one disturbance may mask the evidence of another (see Stone 2006 for a discussion of this topic). Despite the possible interaction of different gear types, some effects on corals could be related to a specific gear type, especially bottom trawling.

Damage to corals was generally least in areas with no observed fishing with bottom trawls (Fig. 7). Overall, for all taxonomic groups combined, there was a significant difference (ANOVA, $p=0.001$ ) in the mean proportion of damaged corals among the levels of fishing intensity with bottom trawls. The mean percentage of damage was $6.8 \%$ in untrawled areas, $7.1 \%$ in low-intensity areas, $13.6 \%$ in medium-intensity areas, and $49.2 \%$ in high-intensity areas. In addition, the proportion of damaged corals was significantly less $(p=0.003)$ in areas with little or no bottom trawling versus areas with medium- and high-intensity bottom trawling. For gorgonians, the mean percent damaged was $5.0 \%$ in untrawled areas, $9.4 \%$ in low-intensity areas, $10.0 \%$ in medium-intensity areas, and $23.1 \%$ in high-intensity areas. For hydrocorals, damage averaged $10.1 \%$ in untrawled areas, $15.8 \%$ in low-intensity areas, and $53.3 \%$ in medium-intensity areas. Hydrocorals were absent in the areas with the highest intensity of bottom trawling. About $40 \%$ of sea whips were damaged in the highest intensity trawled areas compared to $<1 \%$ in other areas.

Although there was a general tendency for coral damage to be greater in areas fished with crab pots, fish pots, or longline gear than in unfished areas, there was no significant difference (ANOVA, p > 0.05) in the proportion of damaged corals among the levels of fishing intensity for these gear types. For example, for 


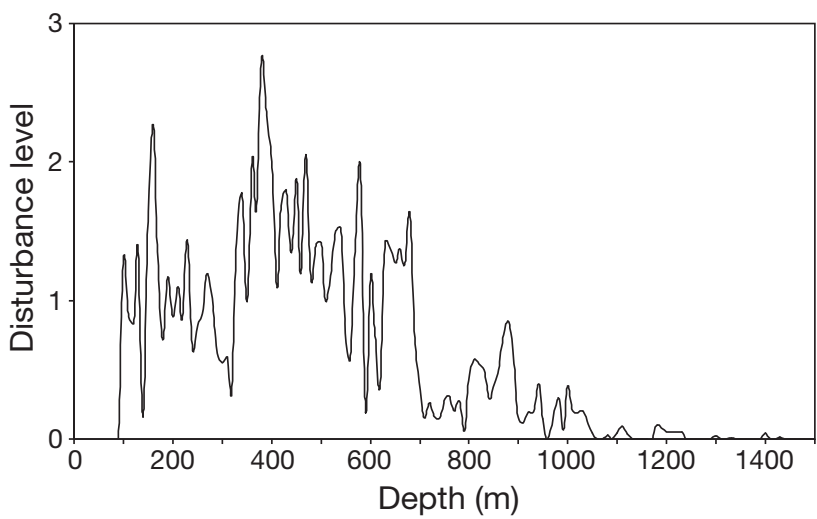

Fig. 4. Average disturbance levels by depth in the central Aleutian Islands based on video transect data. Data were averaged by $10 \mathrm{~m}$ depth bins

longline gear the mean proportion of damaged corals was $4 \%$ in unfished areas and $15 \%$ in fished areas, but due to the high variability within fishery intensity levels this was not statistically significant $(p=0.165$; Fig. 8).

The level of seafloor disturbance did not significantly differ among fishery intensity levels for any of the gear types ( $p$ > 0.05). However, some disturbance could be directly attributable to fishing gear. In some dive tran-
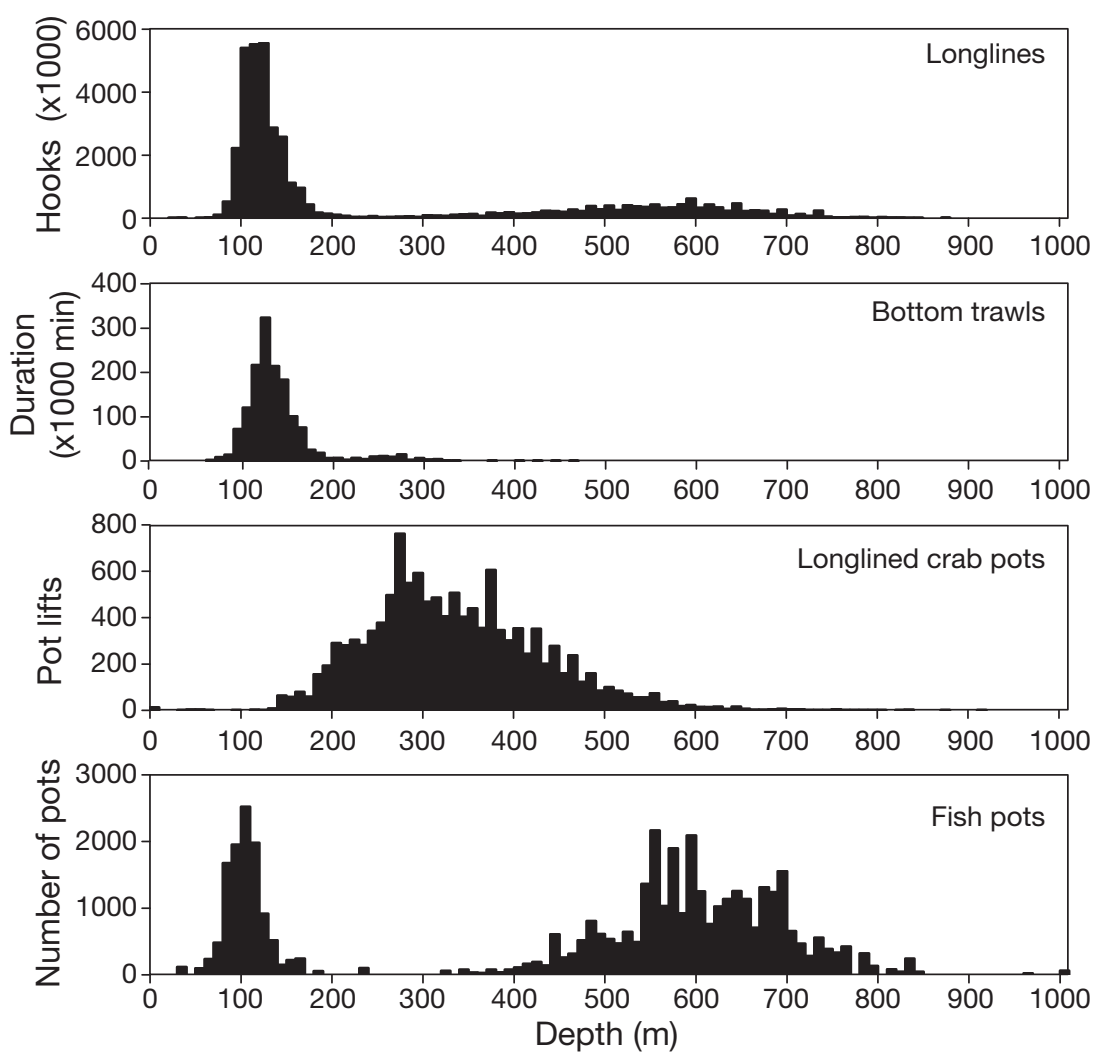

Fig. 5. Depth distribution of observed fishing effort in the central Aleutian Islands during 2000 to 2004 sects there was evidence of bottom trawling: uniform striations in the seafloor caused by the trawl foot rope with gouges caused by the trawl doors. Examination of fishing records indicated that these areas were in the vicinity of high intensity bottom trawling. In addition, $40 \%$ of the dive transects in areas with medium- and high-intensity bottom trawling had mean disturbance values $>1.5$, whereas only $10 \%$ of the areas with little or no bottom trawling had disturbance values $>1.5$.

\section{DISCUSSION}

The goal of the present study was to examine whether seafloor disturbance and damage to corals and sponges are more frequent in heavily fished areas than in areas with little or no fishing. Use of in situ observations of the seafloor enabled us to directly evaluate the relationship between fishing intensity and impacts to corals and sponges over a wide geographic area of the Aleutian Islands. Our study complements the work of Stone (2006) by examining deeper water over a larger geographic area.

Seafloor disturbance was greatest at the depths where most commercial fishing occurred. Between 700 and 1000 m, average seafloor disturbance was 'light', and deeper than $1000 \mathrm{~m}$ seafloor disturbance was mostly 'absent'. Presumably, the gear-induced disturbance that occurred deeper than $700 \mathrm{~m}$ was caused by longlines and pot fisheries since these are the only gears that operated at these depths in the Aleutian Islands. Between 350 and $700 \mathrm{~m}$, in addition to pot and longline hook fisheries, crab pot fisheries operated and there was a corresponding increase in disturbance levels. At depths shallower than 350 m, bottom trawling also occurred. Some of the disturbance we observed was caused by natural events. Disturbance caused by bottom trawls and, to some extent, pot longlines can be clearly defined because they create distinct patterns (Stone 2006). Disturbance caused by longlines with hooks is usually not well defined and can be easily masked by natural events or disturbance created by other gear types.

When the spatial distribution of fishing intensity relative to disturbance and damage levels was examined, areas fished with bottom trawls contained the highest proportion of damaged corals. We infer that consistency of the results 

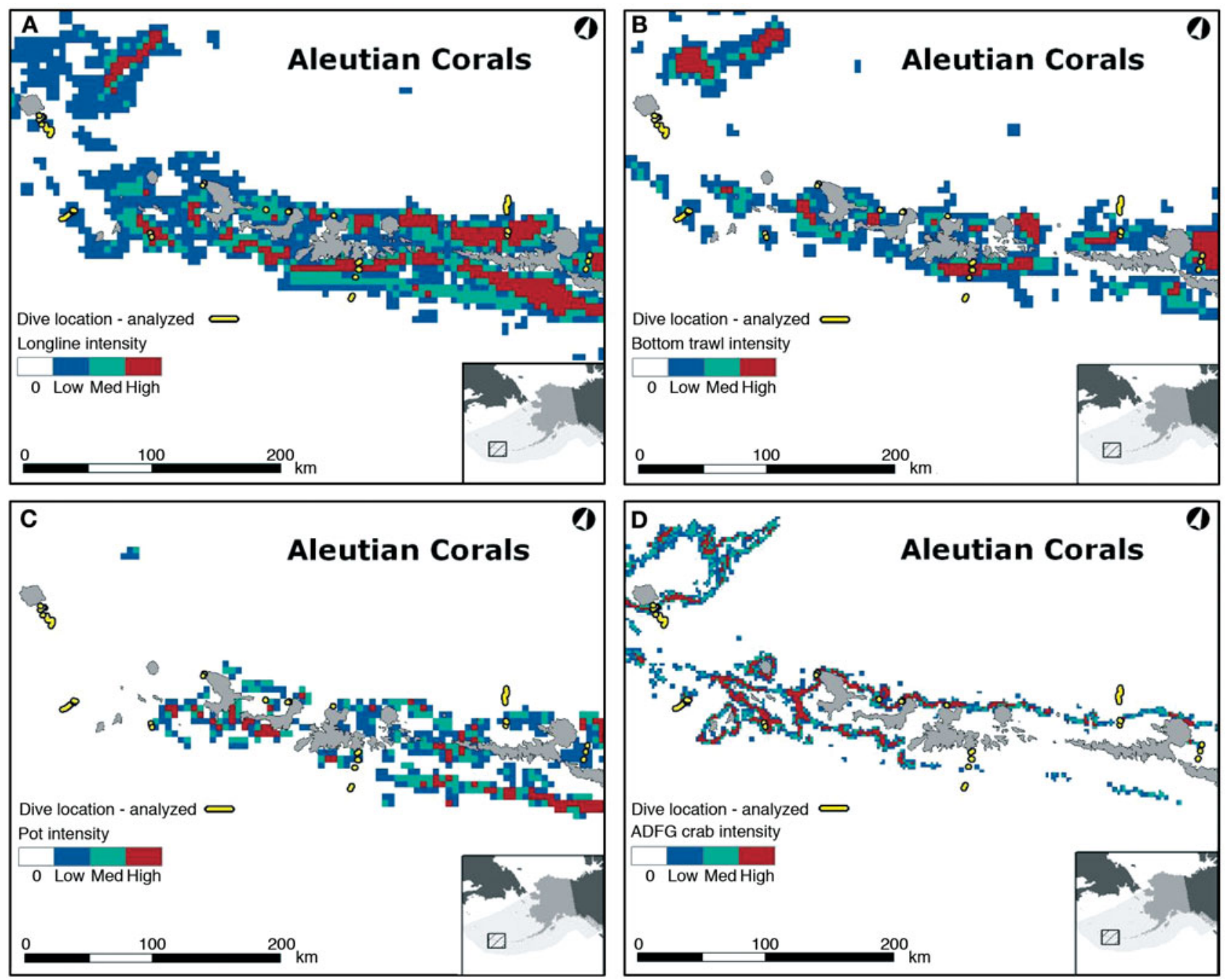

Fig. 6. Spatial distribution of observed fishing effort in the central Aleutian Islands during 2000 to 2004. Data are summarized by $25 \mathrm{~km}^{2}$ blocks for (A) number of longline hooks, (B) duration of bottom trawls, and (C) number of fish pots, and by $4 \mathrm{~km}^{2}$ blocks for (D) number of crab pot lifts. ADFG: Alaska Department of Fish and Game

for bottom trawling is partly because trawl gear tends to be in contact with the seafloor along a continuous path and the footprint can be extensive (10s of m wide). Other gear types have more irregular and narrower contact with the seafloor.

Fishery experts consider ecological impacts to be substantially greater for bottom trawls than pots and longlines (George et al. 2007). A considerable portion of the Aleutian Islands is considered untrawlable even with roller and rockhopper gear because of the prevalence of steep and rocky terrain (Rose \& Jorgensen 2005). Such areas are natural refugia from bottom trawling and often have the highest diversity and abundance of corals and sponges (Stone 2006). Corals and sponges in such steep rocky habitat can be impacted by pot and longline gear. Understanding the impacts of fixed gears such as pots and longlines is dif- ficult because the extent of the area actually disturbed is not easily determined (Auster \& Langton 1999). For example, while longlined crab pots can sometimes cause extensive damage and disturbance, the level depends on whether the gear is retrieved in areas of steep bathymetry or retrieval occurs in strong winds and currents which can intensify the amount of dragging on the seafloor (Stone 2006).

A notable result was that hydrocorals were absent from areas with the heaviest level of bottom trawling. Given that hydrocorals appear to be the most fragile of the coral taxa, it is possible that all hydrocorals had been eliminated from these areas by historical fishing. Reproductive traits of hydrocorals such as internal fertilization and brooding may result in limited potential for hydrocorals to recolonize areas impacted by fishing gear (Brooke \& Stone 2007). Another possibility is that 


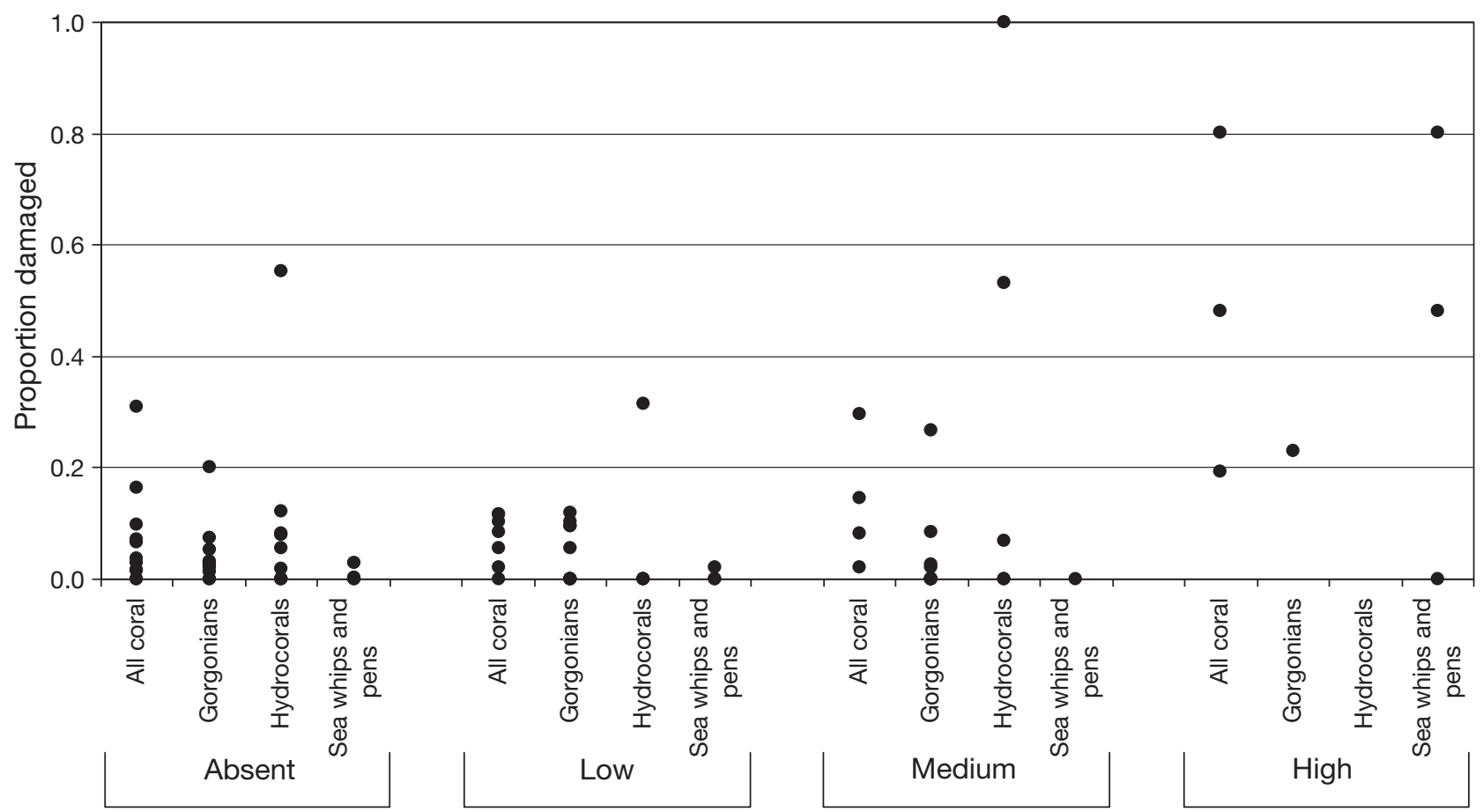

Fig. 7. Proportion of coral damage by bottom trawl fishing intensity in the central Aleutian Islands. Data points are for individual dive transects

the type of habitat with the heaviest bottom trawling is not suitable for hydrocorals. The present study did not consider the effects of historical fishing practices (i.e. prior to 2000); thus, it is difficult to ascertain effects of past fishing.
We conclude that bottom-contact fishing, especially with bottom trawls, causes substantial damage to coral and sponge habitat in the Aleutian Islands. Protective measures in the Aleutian Islands have been implemented to limit bottom trawling to historically fished

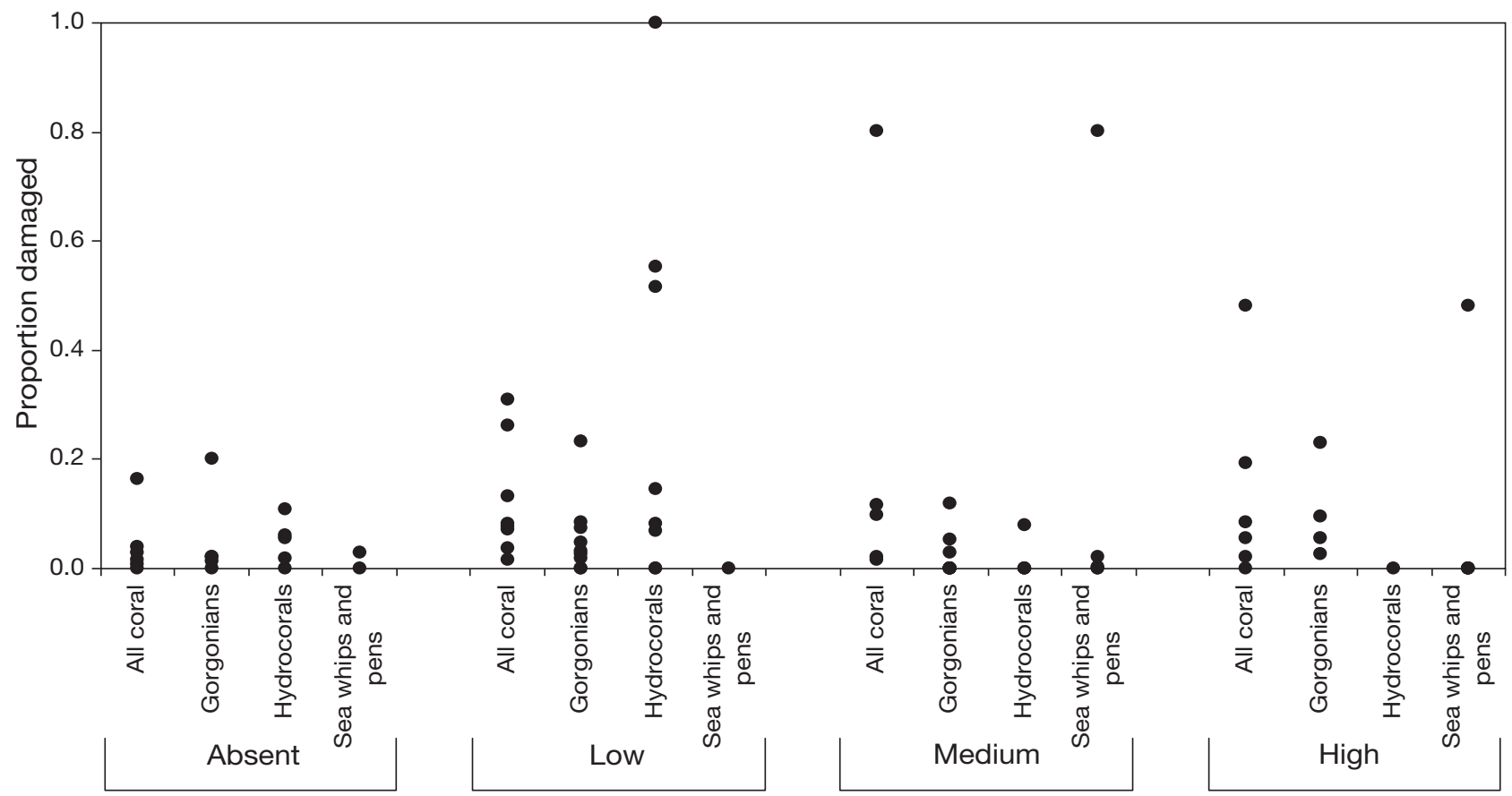

Fig. 8. Proportion of coral damage by longline with hooks fishing intensity in the central Aleutian Islands. Data points are for individual dive transects 
areas (Shester \& Ayers 2005, DOC 2006). While this protective measure may halt the expansion of bottom trawl fishing to unfished areas, the conservation of coral and sponge habitat in fished areas is still a major concern.

Acknowledgements. This study was part of a collaborative research effort on deep sea coral distribution and habitat in the Aleutians undertaken by the National Oceanic and Atmospheric Administration (NOAA) Fisheries, the Alaska Department of Fish and Game, the University of Alaska Fairbanks (UAF), and Moss Landing Marine Laboratories. The project was funded by the North Pacific Research Board, the West Coast \& Polar Regions Undersea Research Center (NOAA), and by NOAA Fisheries and was led by Drs. J. Heifetz (NOAA), J. Reynolds (UAF), and D. Woodby (ADF\&G), and Mr. R. Stone (NOAA). We thank the multiagency field teams and the crews of the RV 'Velero IV', the RV 'Roger Revelle', Delta Oceanographics, and Woods Hole Oceanographic Institution for their support during fieldwork. Thanks also go to E. Brown, C. Martinez and D. Alcorn for reviewing video tapes for data collection. Two anonymous reviewers provided comments that were especially helpful.

\section{LITERATURE CITED}

AFSC (Alaska Fisheries Science Center) (2009) Observer Sampling Manual. Fisheries Monitoring and Analysis Division, North Pacific Groundfish Observer Program. AFSC, Seattle, WA

Andrews AH, Cordes EE, Mahoney MM, Munk K, Coale KH, Cailliet GM, Heifetz J (2002) Age, growth and radiometric age validation of a deep-sea, habitat-forming gorgonian (Primnoa resedaeformis) from the Gulf of Alaska. Hydrobiologia 471:101-110

Andrews AH, Stone RP, Lundstrom CC, DeVogelaere AP (2009) Growth rate and age determination of bamboo corals from the northeastern Pacific Ocean using refined ${ }^{210} \mathrm{~Pb}$ dating. Mar Ecol Prog Ser 397:173-185

Auster PJ, Langton RW (1999) The effects of fishing on fish habitat. In: Benaka LR (ed) Fish habitat: essential fish habitat and rehabilitation. Am Fish Soc Symp 22:150-187

Brooke S, Stone R (2007) Reproduction of deep-water hydrocorals (family Stylasteridae) from the Aleutian Islands, Alaska. Bull Mar Sci 81:519-532

DOC (Department of Commerce) (2006) Fisheries of the Exclusive Economic Zone off Alaska; groundfish, crab, salmon, and scallop fisheries of the Bering Sea and Aleutian Islands Management Area and Gulf of Alaska. Fed Regist 71:124

ESRI (2001) ArcGISTM Spatial Analyst: advanced GIS spatial analysis using raster and vector data. ESRI white paper, available at www.esri.com/library/whitepapers/pdfs/arcgis_ spatial_analyst.pdf

George RY, Okey TA, Reed JK, Stone RP (2007) Ecosystembased fisheries management of seamount and deep-sea coral reefs in US waters: conceptual models for proactive decisions. In: George RY, Cairns SD (eds) Conservation and adaptive management of seamount and deep-sea coral ecosystems. Bull Mar Sci 8:19-30

> Heifetz J (2002) Coral in Alaska: distribution, abundance, and species associations. Hydrobiologia 471:19-28

Heifetz J, Wing BL, Stone RP, Malecha PW, Courtney DL (2005) Corals of the Aleutian Islands. Fish Oceanogr 14 (Suppl):131-138

Heifetz J, Woodby D, Reynolds J, Stone RP (2007) Deep sea coral distribution and habitat in the Aleutian Archipelago. North Pacific Research Board Final Report 304. Available at http://doc.nprb.org/web/03_prjs/r0304_final.pdf

Hiatt T (ed) (2007) Stock assessment and fishery evaluation report for the groundfish fisheries of the Gulf of Alaska and Bering Sea/Aleutian Islands area: economic status of the groundfish fisheries off Alaska, 2005. Alaska Fisheries Science Center, Seattle, WA. Available at www.afsc.noaa. gov/refm/docs/2005/economic.pdf

Krieger KJ (2001). Coral (Primnoa) impacted by fishing gear in the Gulf of Alaska. In: Willison JHM, Hall J, Gass SE, Kenchington ELR, Butler M, Doherty P (eds) Proc 1st Int Symp Deep-Sea Corals. Ecology Action Centre and Nova Scotia Museum, Halifax, p 106-116

Malecha PW, Stone RP, Heifetz J (2005). Living substrate in Alaska: distribution, abundance, and species associations. In: Barnes PB, Thomas JP (ed) Benthic habitats and the effects of fishing. Am Fish Soc Symp 41:289-299

Morgan LE, Etnoyer P, Scholz AJ, Mertens M, Powell M (2005) Conservation and management implications of deep-sea coral and fishing effort distributions in the Northeast Pacific Ocean. In: Freiwald A, Roberts JM (eds) Cold-water corals and ecosystems. Springer, Berlin, p 1171-1187

Rose CS, Jorgensen EM (2005) Spatial and temporal distributions of bottom trawling off Alaska: consideration of overlapping effort when evaluating the effects of fishing on habitat. In: Barnes PB, Thomas JP (ed) Benthic habitats and the effects of fishing. Am Fish Soc Symp 41:679-690

Shester G, Ayers J (2005) A cost effective approach to protecting deep-sea coral and sponge ecosystems with an application to Alaska's Aleutian Islands region. In: Freiwald A, Roberts JM (eds) Cold-water corals and ecosystems. Springer, Berlin, p 1151-1169

Sokal RR, Rohlf FJ (1969) Biometry: the principles and practice of statistics in biological research. WH Freeman, San Francisco, CA

> Stone RP (2006) Coral habitat in the Aleutian Islands of Alaska: depth distribution, fine-scale species associations, and fisheries interactions. Coral Reefs 25:229-238

Stone RP, Shotwell SK (2007) State of the deep coral ecosystems of the Alaska Region: Gulf of Alaska, Bering Sea, and the Aleutian Islands. In: Lumsden SE, Hourigan TF, Bruckner AW, Dorr G (eds) The state of deep coral ecosystems of the United States. NOAA Tech Memo CRCP-3, Silver Spring, MD, p 65-108

> Woodby D, Carlile D, Hulbert L (2009) Predictive modeling of coral distribution in the central Aleutian Islands, USA. Mar Ecol Prog Ser 397:227-240 